Article

\title{
Optimal Location Analysis of Delivery Parcel-Pickup Points Using AHP and Network Huff Model: A Case Study of Shiweitang Sub-District in Guangzhou City, China
}

\author{
Zilai Zheng ${ }^{1, *}$, Takehiro Morimoto ${ }^{2}$, and Yuji Murayama ${ }^{2}$ (I) \\ 1 Graduate School of Life and Environmental Sciences, University of Tsukuba, 1-1-1 Tennodai, Tsukuba, \\ Ibaraki 305-8572, Japan \\ 2 Faculty of Life and Environmental Sciences, University of Tsukuba, 1-1-1 Tennodai, Tsukuba, \\ Ibaraki 305-8572, Japan; tmrmt@geoenv.tsukuba.ac.jp (T.M.); mura@geoenv.tsukuba.ac.jp (Y.M.) \\ * Correspondence: s1830205@s.tsukuba.ac.jp; Tel.: +81-80-4068-7266
}

Received: 26 February 2020; Accepted: 23 March 2020; Published: 25 March 2020

\begin{abstract}
The use of parcel-pickup points (PPPs) is an effective approach for solving the last-mile problem. However, few studies provide specific guidance for the optimal organization of PPPs. Here, a geographic information system(GIS)-based hybrid model was developed combining the widely used analytic hierarchy process (AHP) multi-criteria analysis method with the Huff model that predicts the number of visiting customers to determine the optimal facility for collaboration and service as a PPP. Using this model, a decision-maker can select the highest-ranking facility or use the fluctuation ranking graph to determine a priority list of candidate facilities according to the appropriate PPP service distance. Our findings suggest that the optimal candidate facility should be located near high population density areas, a dense road network, and few geographic barriers. The facility should have a high attractiveness value, long business hours, and convenient access to public transportation, cover a large, high-population area, and should be a retail chain store. Based on these findings, the AHP method can improve the accuracy of obtaining the facility attractiveness value using the Huff model. Facility attractiveness has a strong effect on the resulting number of customers in the case of acceptably long distances to residential buildings.
\end{abstract}

Keywords: parcel-pickup point(PPP); Geographic Information System(GIS); Analytic Hierarchy Process(AHP); network Huff model; optimal location

\section{Introduction}

Last-mile delivery, which is the terminal delivery in the shipping of e-commerce, is the most costly, most contaminating, and least efficient component of the entire logistics process [1-6]. It is considered to be the most crucial and difficult-to-control phase in e-commerce because it requires the delivery of the right goods to the right place at the right time. Many e-commerce companies and express enterprises consider effective delivery systems to be essential competitive advantages $[7,8]$ and have attempted to implement novel solutions to the aforementioned problems by tackling bottlenecks using approaches such as attended parcel-pickup points (PPPs) (i.e., neighbors' homes, community guards, small shops), unattended PPPs (i.e., communal reception box) [9-12], and delivery drones [13], thus, providing the customers with a flexible, convenient, and comfortable way of receiving parcels. In this paper, we focus on the attended PPPs.

PPPs are rapidly developing in China [14]. The most common one is the "Cainiao parcels logistics station" introduced by the e-commerce company giant Ali Baba. This approach allows customers to 
collect their packages from nearby shops. Ali Baba franchised the existing small shops to add the parcel reception service instead of setting up a new service [12]. This original method of business collaboration can result in a mutually beneficial situation. For e-commerce companies such as Ali Baba, this delivery method can reduce the cost of setting up new facilities and quickly establish a distribution service coverage network. Facility owners can earn additional revenue from providing parcel reception services, and acquire more in-store traffic, thus, contributing to the shop's profits. Customers can have parcels delivered to their preferred place and time through this new delivery model [15]. However, the PPP network also has some constraints. Some areas do not have physical shops, and some facility owners refuse to join the delivery network because storage space is limited and expensive.

Despite the range and number of studies on PPPs, only a few provide accurate information for decision-makers on how to choose a location for PPP. Research studies on the organization of PPPs are quite scarce, and case studies are limited [16]. Researchers have focused their attention on the distribution characteristics of the PPP and their relationship with spatial and non-spatial factors. PPPs are more likely to be located in urban residential areas, and the PPP network is directly related to the population density, accessibility to residents, and the residents' preferences [16-20]. However, previous studies have not provided a feasible method for quantifying and combining these factors to analyze and identify the optimal location for PPP. With the rapid development of the e-commerce business, managers urgently need accurate and credible decision-making data to help them deploy PPPs.

The present study seeks to quantify the aforementioned factors and find a suitable model to address the PPP deployment problem. In many research methods used for location selection, the geographic information system (GIS) is rapidly becoming a popular tool that plays a significant role in many applications for predicting and selecting a new site location in support of the extensive spatial queries [21]. One of the advantages of GIS is its data visualization capacity that can make complex data understandable and, thus, help decision-makers reach appropriate decisions [22,23]. Another advantage is its ability to cope with a considerable amount of quantitative data and connect the Geodata to relational databases between them. The Huff model is a gravity-based spatial interaction model that calculates the probabilities of the consumers' selection of a candidate facility to predict its sales potential $[24,25]$. This probability is directly proportional to the facility's attractiveness and inversely proportional to the distance between the customer's residential building and the facility [26]. The network Huff model has been applied in the location analysis of a transport road network. However, a facility's attractiveness is inevitably affected by many factors. Multi-criteria decision analysis (MCDA) is a method for assisting decision-makers in evaluating the alternatives according to different criteria [27]. The analytic hierarchy process (AHP) is an MCDA approach first developed by Saaty in the 1970s that is widely used to deal with this complex decision problem due to its excellent mathematical properties [28]. AHP uses a quantitative comparison method based on pairwise comparisons of criteria and alternatives. Therefore, GIS-based technology provides a possible approach for the decision-makers to collect, analyze, and visualize complicated geospatial information; the Huff model offers a method for combining the population, distance to the facility, and customer preference variables and the AHP method provides a solution for dealing with the complex selection criteria.

Thus, the main aim of this study was to develop a hybrid GIS-based AHP and Huff model for identifying a suitable location for PPP in a typical residential area by (1) determining the factors affecting the residents' selection of a PPP, (2) evaluating the relative importance of these factors using the AHP method, (3) calculating the attractiveness of the facilities, and (4) predicting the number of customers at the candidate facilities.

\section{Materials and Methods}

\subsection{Study Area and Data}

China has the largest e-commerce market in the world, with over $40 \%$ of global e-commerce transactions originating from the country as of 2017 [29]. In this work, we chose Guangzhou as the 
research city, because it has been ranked highest in parcel receipts in China for five consecutive years from 2014 to 2018 [30-34]. As shown in Figure 1, the study area is in the central area of the Shiweitang sub-district of Guangzhou. The Shiweitang sub-district, located in the southeast of Liwan district, has a population of 57,192 in 2010 and covers an area of $5.18 \mathrm{~km}^{2}$ [35], containing different kinds of residential buildings, including condominiums, apartments, and urban village houses. Since this area is filled with different types of residential buildings and has a high population density, this study aims to identify suitable facilities for the introduction of a PPP, as it appears to be significant and beneficial for the residents in the area.

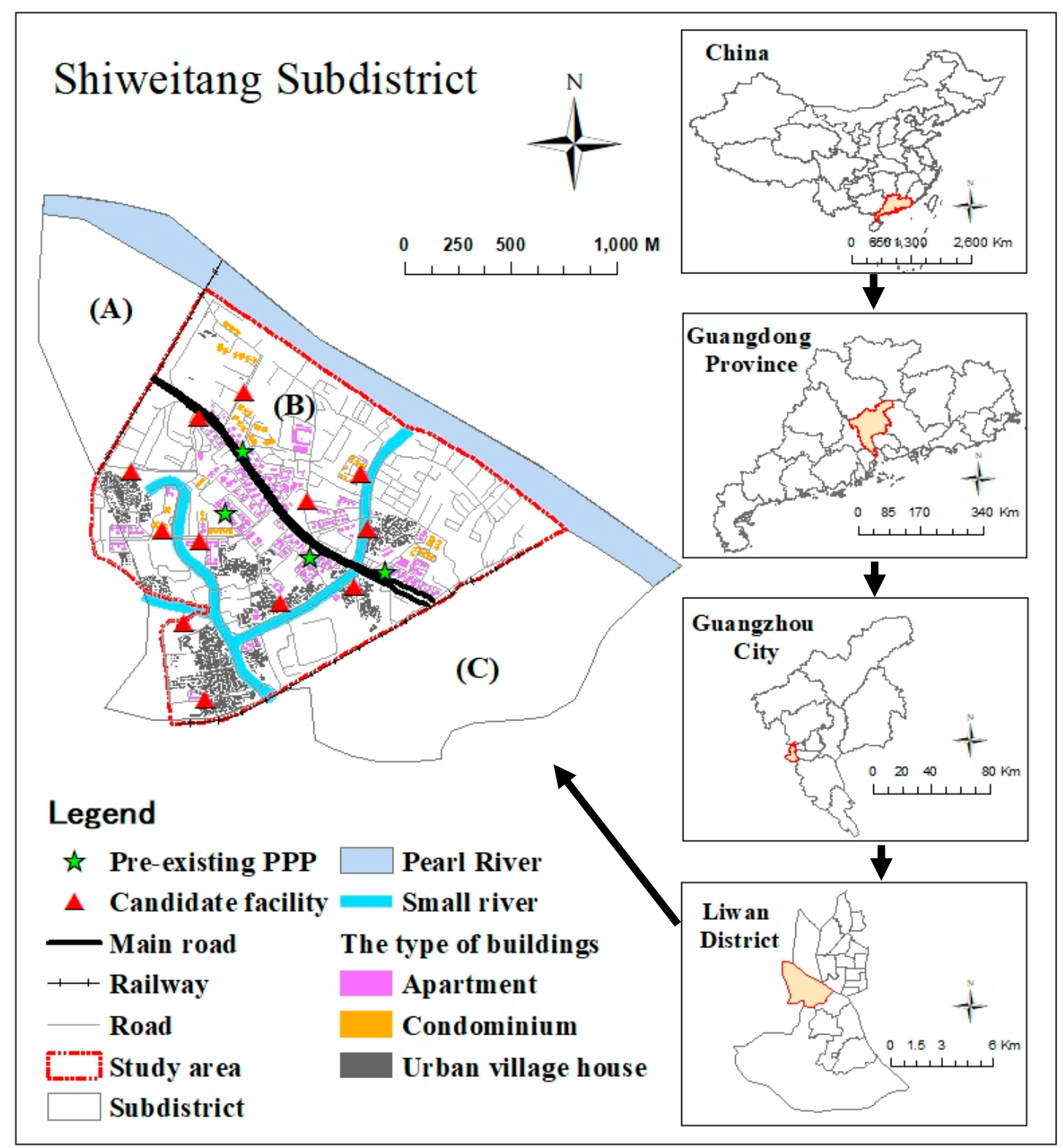

Figure 1. Study area; locations of environmental components and pre-existing and candidate PPP facilities.

As illustrated in Figure 1, two railroads-Zhujiangqiao and Guangmao-divide the Shiweitang sub-district into three areas. The upper west area labeled (A) contains the GuangFo distribution center and the large Jiaokou long-distance bus terminal, and the lower east area (C) includes the largest tea-leaf wholesale trade market in southern China. The central area (B), which was chosen as the study 
area, contains the greatest number of residential housing buildings in the sub-district. Figure 2 shows the local environment of the study area.

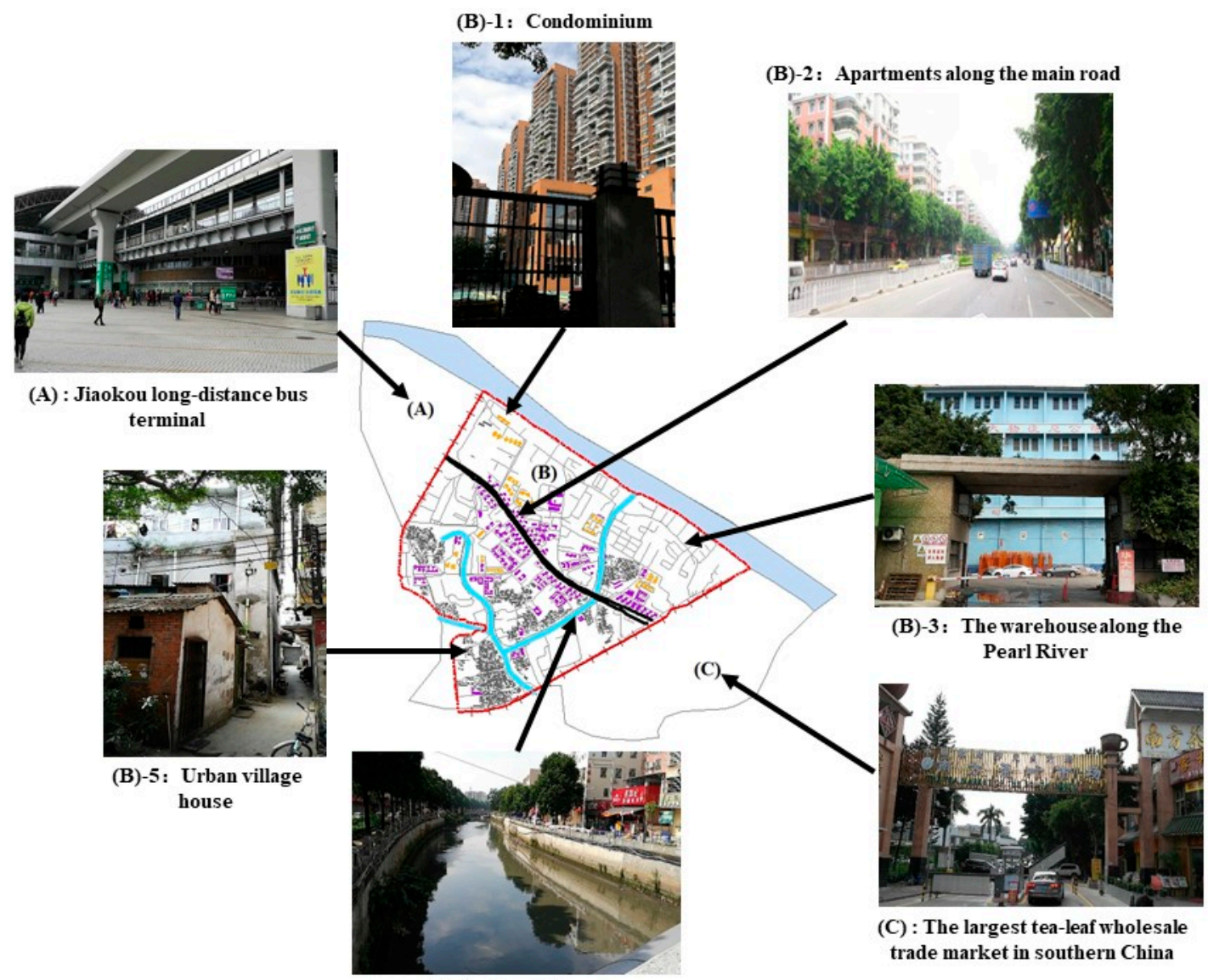

(B)-4: Small river

Figure 2. Urban and environmental development components of the study area (Photos taken by the author in 2018).

Table 1 shows the data used in this paper. Gaode Maps and Baidu Maps are the most commonly used electronic maps for daily navigation in China because they contain accurate and up-to-date information. We found that Gaode maps [36] had more detailed road data, including alleys, regarding one community in the study area. The building data included partial floor attribute data but lacked information on the building use. We identified residential buildings using Baidu Maps' street view function and completed the floor data based on the data available on the website of the Lianjia real estate agency [37] and fieldwork. We classified residential buildings into three categories: condominiums, apartments, and urban village houses. Distinguishing building use in an urban village is difficult due to the lack of regulation for a large number of urban village residential buildings and their small footprint [38]. All of the buildings in the urban village area were considered to be residential buildings. We added one floor to the missing data of this type of housing because most urban village houses in the study area had one floor. A population census is conducted every 10 years in China, and the latest census was carried out in 2010. 
Table 1. List of data used.

\begin{tabular}{|c|c|c|c|c|}
\hline Type & Data & Source & Format & Description \\
\hline \multirow{5}{*}{ Spatial } & $\begin{array}{l}\text { Administrative } \\
\text { boundary }\end{array}$ & $\begin{array}{c}\text { National Geomatics Center of } \\
\text { China (2017) }\end{array}$ & Vector (Polygon) & \\
\hline & Road & \multirow{4}{*}{$\begin{array}{l}\text { Ministry of Land and } \\
\text { Resources of the People's } \\
\text { Republic of China (2015) }\end{array}$} & Vector (Line) & \multirow{4}{*}{$\begin{array}{l}\text { Updated by ArcMap } \\
\text { software according to } \\
\text { the Screenshot of Gaode } \\
\text { maps Georeferencing }\end{array}$} \\
\hline & Bus-stop & & Vector (Point) & \\
\hline & Building & & Vector (Polygon) & \\
\hline & Urban village area & & Vector (Polygon) & \\
\hline Non-spatial & Population census & $\begin{array}{l}\text { National Bureau of Statistics of } \\
\text { China in } 2010\end{array}$ & & \\
\hline
\end{tabular}

\subsection{Methodology}

Figure 3 shows the method used to conduct this research. It mainly consisted of four parts: (1) defining the blank service area and candidate facilities; (2) estimating the population of residential buildings; (3) calculating the attractiveness of different candidate facilities using AHP; and (4) estimating the number of customers of the potential facilities using the Huff model.

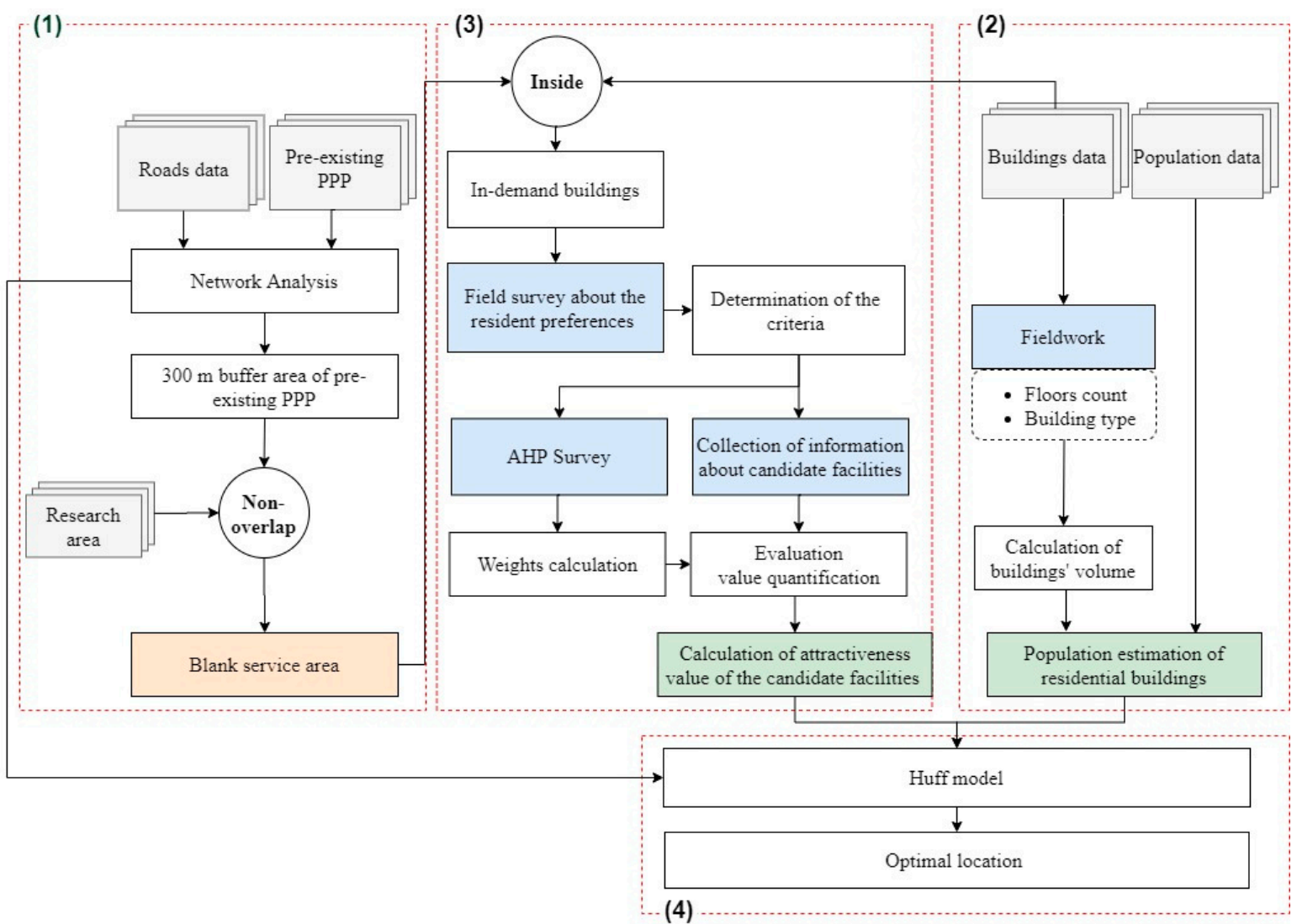

Figure 3. Methodological framework.

\subsubsection{Defining Blank Service Areas and Candidate Facilities}

A $300 \mathrm{~m}$ service area for each pre-existing PPP was created based on the road network. We assumed that in the region outside the above area, termed the "blank service area," there were no PPP services, and all residents in this area required PPP service. Customers were located in the residential buildings within the blank service area. These residential buildings were termed "in-demand buildings." As illustrated in Figure 4, the green area represented the service area of the four pre-existing PPPs. The yellow areas represented the central points of each residential building in the blank service area and were designated as demand points. 


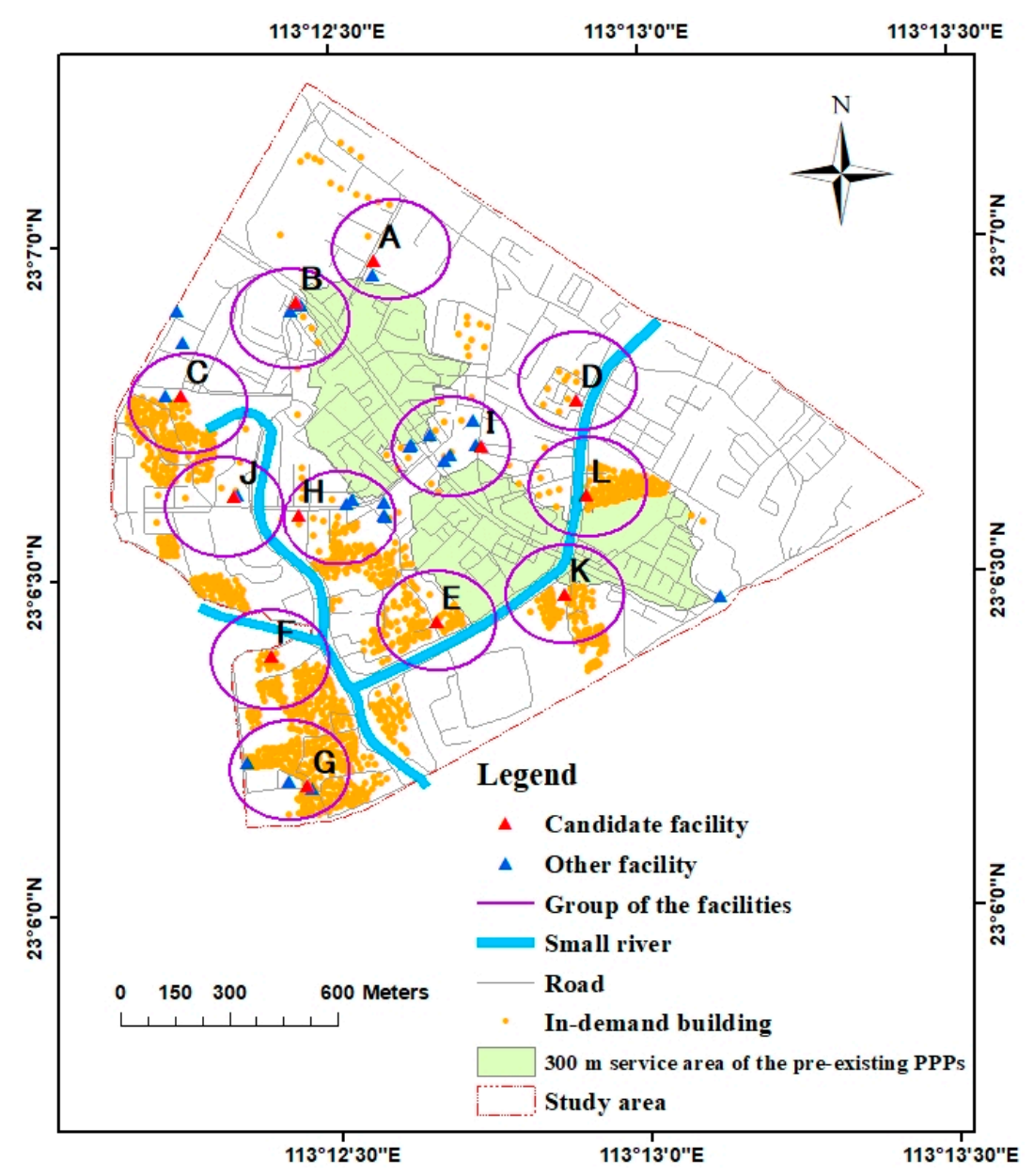

Figure 4. Location of the 12 selected candidate facilities.

According to our literature review, PPPs in France mainly depend on small local facilities, such as press kiosks, bars, florists, and tobacco shops [16]. In the UK, PPPs have been established in frequently visited public facilities in urban areas, such as post offices, petrol stations, and small shops [9]. In Guangzhou, the pre-existing PPP providers collaborate with retail shops (e.g., supermarkets, convenience stores) and service shops (e.g., car maintenance shops, real estate shops). Thus, in this study, we considered the following types of facilities as potential PPP facilities: supermarkets (including convenience stores), car maintenance shops, computer/phone repair shops, lottery shops, pharmacies, and real estate shops. Information on the location of these facilities in the blank service area was collected via Baidu coordinate system [39]. On this website, the keywords for parcel pickup points were used as the search criteria; this immediately displayed all the relevant points, including information on latitude and longitude. Coordinate conversion is conducted before the points are added to ArcMap due to the BD-09 coordinate system used by Baidu maps. There are 35 facilities in the blank service area, of which three are located far from the location of the customers and, thus, are not considered.

In the subsequent step, the AHP method was applied in a pair-comparison of all candidate facilities to calculate their respective attractiveness indices. A high number of candidate facilities leads to a high computational cost of pair-comparison. In this study, for the cases where a location had multiple facilities, we selected one representative facility as a candidate facility to reduce the total number of facilities. We divided the 32 facilities into 12 groups according to their distribution and mutual aggregation that is represented by purple ellipses in Figure 4. In each group, we only selected one facility, represented by a red triangle, as a candidate facility. If there was more than one facility in the group, we created a $300 \mathrm{~m}$ service area for each alternative using the ArcMap tool and, then, 
selected the facility with the largest population in the service area as the candidate facility. Ultimately, we selected 12 candidate facilities for analysis.

\subsubsection{Estimating the Population of Residential Buildings}

Population data at the building level is necessary for microanalysis. However, the minimum statistical unit of the Chinese census demographics data is a sub-district. Because detailed population data are scarce, estimations of the population play a crucial role.

Lwin and Murayama [40] proposed a method of obtaining an accurate building population for micro-spatial analysis using the buildings' volume and census tract data of the area.

The volumetric method is expressed mathematically as:

$$
B P_{i}=\left(\frac{C P}{\sum_{k=1}^{n} B A_{k} B F_{k}}\right) B A_{i} B F_{i}
$$

where $\mathrm{BPi}$ is the population in the building $\mathrm{i}, \mathrm{CP}$ is the population of the census tract, $\mathrm{BAi}$ is the footprint area of building $i$, BFi is the number of floors of building $i, i$ and $k$ are summation indices, and $\mathrm{n}$ is the number of buildings that fall inside the $\mathrm{CP}$ polygon [40].

Figure 5 illustrates the estimated population in the study area obtained using the volumetric approach. The population of the buildings in the urban villages is small because these buildings are low-rise buildings and cover a small area. The high-population buildings are the high-rise condominiums or apartments with large footprints.

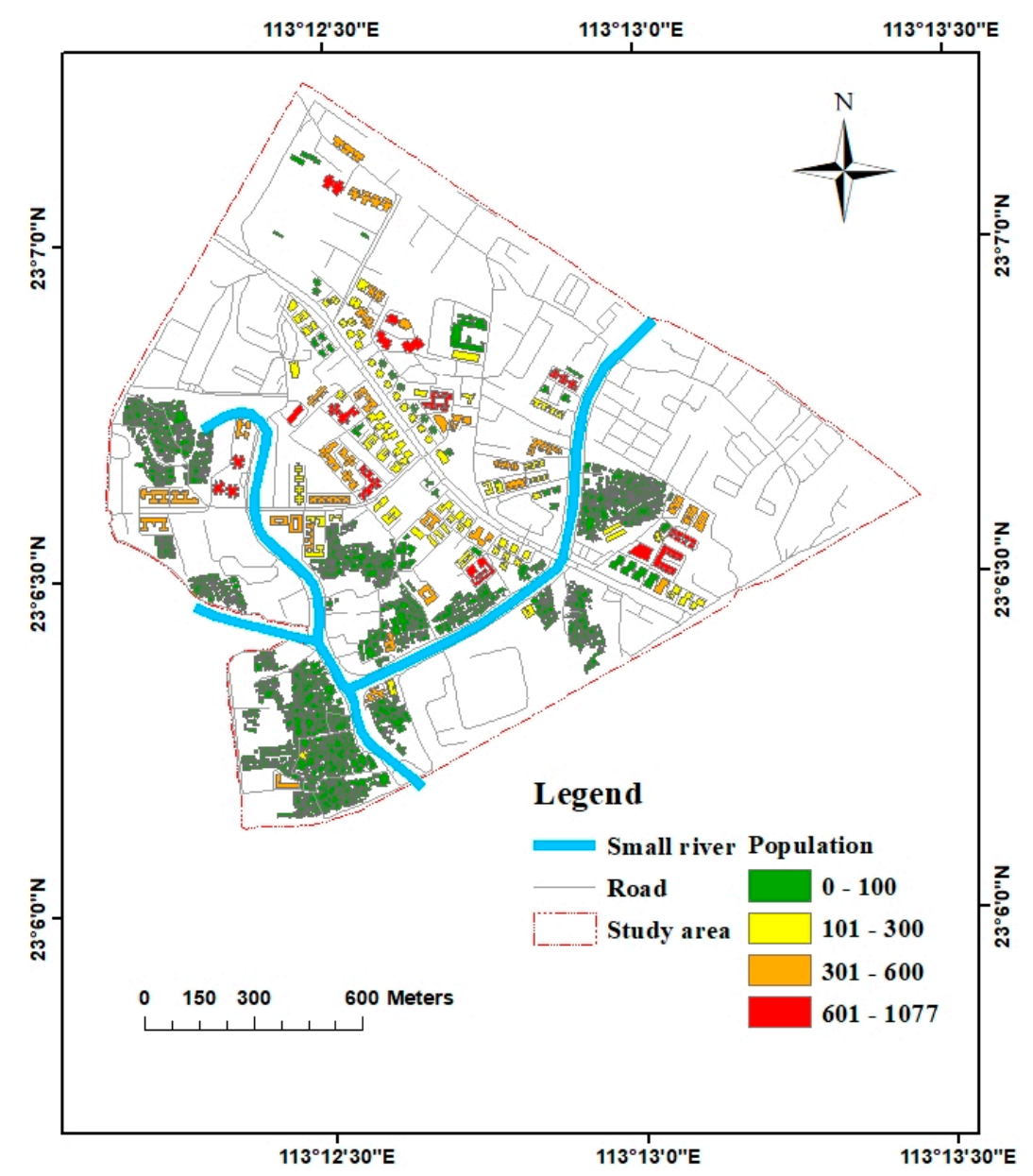

Figure 5. Estimated population of the residential buildings. 


\subsubsection{Calculating the Attractiveness of Different Alternative Facilities Using AHP}

AHP is an efficient approach for MCDA applications [41], which combines qualitative and quantitative analysis with excellent reliability and an extensive range of applications [42]. We carried out the following steps of the AHP method:

- Determining the criteria

The selection of the criteria for the AHP method has been mainly based on the reviewed literature or expert recommendations $[43,44]$. However, this approach is not suitable for cases covered by only a few research studies. We attempted to carry out a survey of the residents in the research area to determine the factors influencing their judgment of the facility's attractiveness. This method of determining the AHP's criteria is one of the novel features of this work.

The selection of sample buildings in the resident preferences survey was based on the proportion of the three different types of residential buildings. We also ensured that the sample sites were spread throughout the blank service area. Questionnaires were administered to 212 residents who responded to queries about their attributes (gender, age, family composition), their willingness to use the PPP, their psychological characteristics, an acceptable distance to the PPP, and the factors affecting the location selection. Most of the questions required the selection of only one answer out of multiple choices provided except for the factors affecting the location selection for which respondents were allowed to select as many factors as were applicable.

Table 2 shows the results obtained for the factors affecting the attractiveness of the facility. It was found that $99 \%$ of the respondents would consider the operation hours of a facility, followed by the convenience and attributes of the PPP. Only 10\% of the respondents considered the size of the staff. Thus, four critical factors determined the attractiveness of a facility: its operation hours, distance to bus stops, type of facility, and area.

Table 2. Resident preferences survey: factors affecting the attractiveness of the facility.

\begin{tabular}{cc}
\hline Factors & Percentage \\
\hline Business hours & $99 \%$ \\
Distance to bus stops/subway station & $85 \%$ \\
Facility type & $76 \%$ \\
Facility area & $49 \%$ \\
Number of facility staff & $10 \%$ \\
\hline
\end{tabular}

The results for the acceptable distance to PPP indicated by the residents are shown in Table 3. Nearly half of the respondents could accept a distance range that was within $300 \mathrm{~m}$, followed by $500 \mathrm{~m}$ and $1000 \mathrm{~m}$, while all residents were opposed to a range that was greater than $1000 \mathrm{~m}$. In the next analysis step, we will use these distances to determine the optimal facilities.

Table 3. Resident preferences survey: acceptable distance.

\begin{tabular}{cc}
\hline Acceptable Distance & Percentage \\
\hline $100 \mathrm{~m}$ & $15 \%$ \\
$300 \mathrm{~m}$ & $47 \%$ \\
$500 \mathrm{~m}$ & $34 \%$ \\
$1000 \mathrm{~m}$ & $4 \%$ \\
$>1000 \mathrm{~m}$ & $0 \%$ \\
\hline
\end{tabular}

- $\quad$ Building the AHP structure

The general hierarchy structure of AHP consists of three fundamental levels. As illustrated in Figure 6, the overall objective of AHP in this study is to quantify the attractiveness of the 12 candidate 
facilities. The four decision criteria are determined by the questionnaire described in the preceding section and the alternatives are the 12 candidate facilities. The overall decision matrix is expressed as:

$$
X=\left(X_{i j}\right)_{12 * 4}
$$

where $X$ denotes the overall attractiveness and $X_{i j}$ denotes the attractiveness of the facility $i$ for criteria $j$.

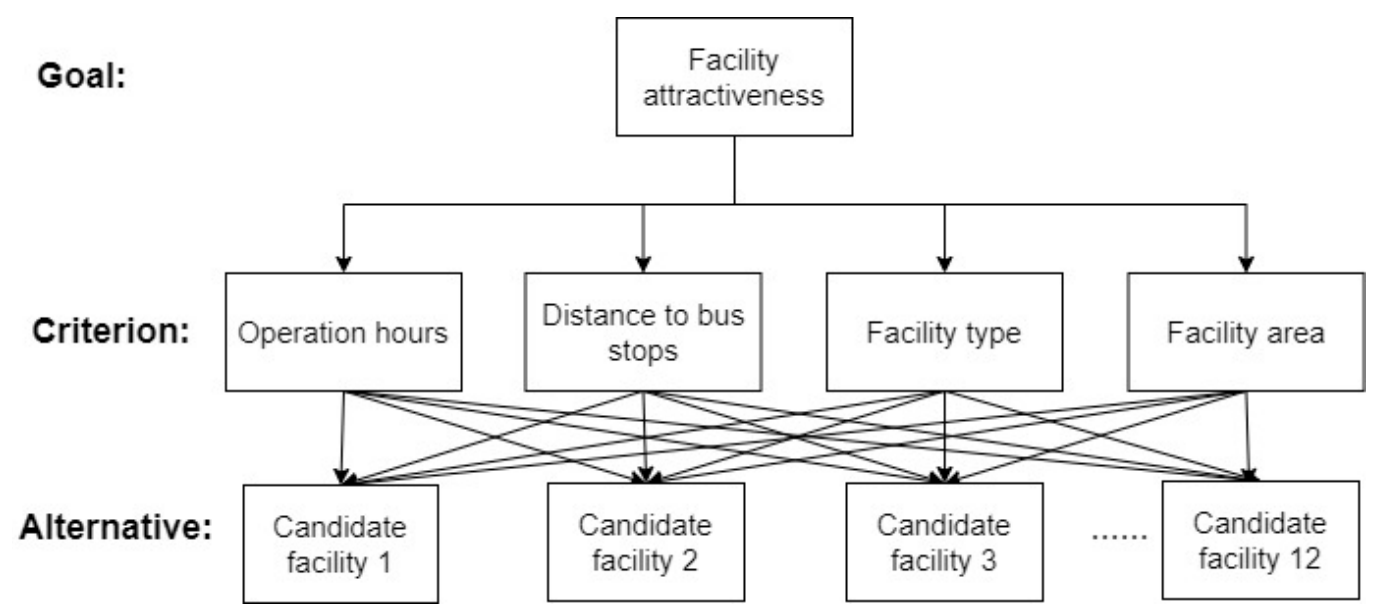

Figure 6. AHP structure.

- Computing the matrix of criteria weights and alternative weights

The AHP creates a pairwise comparison matrix to determine the weights of the criteria. The relative importance scale with a numerical scale between one to nine derived from the psychophysical law of Weber-Fechner is the most widely used AHP scale [45,46]. To determine the consistency of the judgments from each pairwise comparison, the consistency index $(\mathrm{CI})$ of the matrix was calculated and compared with a random index (RI) to obtain the consistency ratio (CR) [41]. If the CR is less than 0.1 , the judgments in the pairwise comparison matrix are considered to be consistent [47]. We administered an AHP questionnaire among the potential customer representatives to obtain these data. Ten representative households that frequently shopped online were selected from different residential building types to fill the questionnaire: four from the condominium, four from the apartment, and two from the urban village. After collecting the data, we checked the consistency ratio (CR) and analyzed the data using a free online tool named the AHP Online Calculator-Business Performance Management Singapore (BPMSG) [48]. Nine households' data with a CR value that was below 0.1 qualified and one household's data with a CR value of 0.29 was invalid. We then constructed the matrix $\mathrm{w}$ of the criteria and normalized the pairwise comparison data to obtain the weights using the online tool.

In this paper, with 12 alternatives and four criteria, the residents had to complete 264 questions to generate the weights of the alternatives. A comparison of the quantity data is tedious and inefficient, particularly in the cases with a high number of criteria and alternatives. Some researchers attempted to reduce the complexity of the preference eliciting process (i.e., by employing incomplete pairwise comparisons and a sparse structure) $[49,50]$. In this study, since the values of the alternatives in the criteria were mainly quantitive data, we suggested a simple approach for obtaining the relative importance scale in terms of one to nine, instead of a pairwise-comparison using a questionnaire. The equations are described below. 
For example, the importance scale Bij was derived using the alternatives of $S i$ and $S j$, which are the matrix values in the interval [Max S, Min S]. If a larger value corresponds to better performance (such as size, business hour), and $\mathrm{Si} \geq \mathrm{Sj}$, Bij is calculated as:

$$
B_{i j}=8 \times \frac{S_{i}-S_{j}}{\operatorname{Max} \mathrm{S}-\operatorname{Min} \mathrm{S}}+1
$$

If a smaller value corresponds to better performance (such as distance), and $\mathrm{Si} \leq \mathrm{Sj}, \mathrm{Bij}$ is calculated as:

$$
B_{i j}=8 \times \frac{S_{i}-S_{j}}{\operatorname{Min} \mathrm{S}-\operatorname{Max} \mathrm{S}}+1
$$

The attractiveness of each candidate facility is computed using the criteria matrices $\mathrm{w}$ and the alternative matrix $\mathrm{S}$ obtained in the preceding step:

$$
\mathrm{V}=\mathrm{S}^{*} \mathrm{~W}
$$

\subsubsection{Estimating the Number of Customers of the Potential Facilities Using the Huff Model}

The Huff model assumes the flow between the facility and the demand to predict consumer spatial behavior. While in the previous study, the attractiveness was mainly based on the facility's area, in this study, we imported the index of facility attractiveness calculated using the aforementioned steps. The probability (Pij) that a consumer living in $i$ will select the facility $j$ is calculated using the following formula:

$$
P_{i j}=\frac{A_{j} / D_{i j}^{\lambda}}{\sum_{n=1}^{n} \frac{A_{j}}{D_{i j}^{\lambda}}}
$$

where Pij is the possibility of a customer located in the building i selecting facility $j, A j$ is the attractiveness of facility $j$, Dij is the distance from $i$ to $j, \lambda$ is a parameter that considers the effect of distance on shopping, and $\mathrm{n}$ is the number of the facilities that can be accessed by the people living in building i.

The parameter estimated for Tajima, for which $\lambda$ equals 2 , was considered to be the most typical value for the attractiveness parameter [51,52]. This empirical parameter was used for the analyses conducted in this study.

The estimated number of consumers in the potential facility $j$ is calculated using the following formula:

$$
\mathrm{Bj}=\sum_{j=1}^{n} P_{i j} \times S_{i}
$$

where $\mathrm{B} j$ is the predicted number of residents visiting the facility $\mathrm{j}, \mathrm{Si}$ is the total number of residents in the building $\mathrm{i}$, and $\mathrm{Pij}$ is the probability that residents living in the building $\mathrm{i}$ will visit facility $\mathrm{j}$.

Here, we consider the in-demand Building 1 in Figure 7 as an example of the calculation in order to illustrate the method. Figure 7 shows the allocation of PPP within $300 \mathrm{~m}$ and the routes from Building 1 to facilities in the road network analysis using ArcMap. The distance in network analysis in (b) is the same as the data in (a). This verifies that the allocation function in ArcMap is consistent with the calculation of the road network distance.

The estimated population of Building 1, the attractiveness of facilities $\mathrm{J}$ and $\mathrm{H}$, and the distance between these facilities are used as input into the Huff model for verification. The predicted number of the residents living in Building 1 and visiting facilities $\mathrm{J}$ and $\mathrm{H}$ calculated using the Huff model formula is consistent with the data from the analysis results table produced using the network allocation 
function in ArcMap. In this study, we used this function after the Huff model to rapidly obtain accurate calculation results:

$$
\begin{gathered}
P_{1 J}=\frac{0.082 / 295.35^{2}}{\frac{0.082}{295.35^{2}}+\frac{0.131}{111.136^{2}}} \quad P_{1 H}=\frac{0.131 / 111.36^{2}}{\frac{0.082}{295.35^{2}}+\frac{0.131}{111.36^{2}}} \\
B_{J}=885.23 * P_{1 J}=721.44 \quad B_{H}=885.23 * P_{1 H}=163.85
\end{gathered}
$$

The result for the consumers predicted to use the facility depended on different acceptable distances. The ranking of the 12 candidate facilities changes according to the acceptable distance. A chart of the ranking fluctuation of each candidate facility with a distance ranging between $100 \mathrm{~m}$ and $1000 \mathrm{~m}$ was used for the analysis of the optimal location.

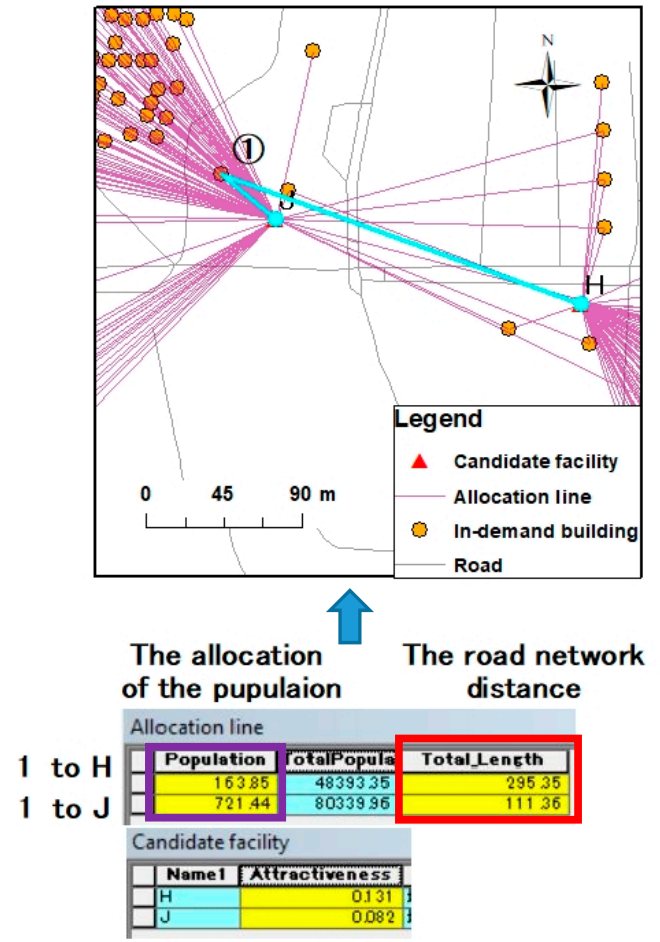

(a)

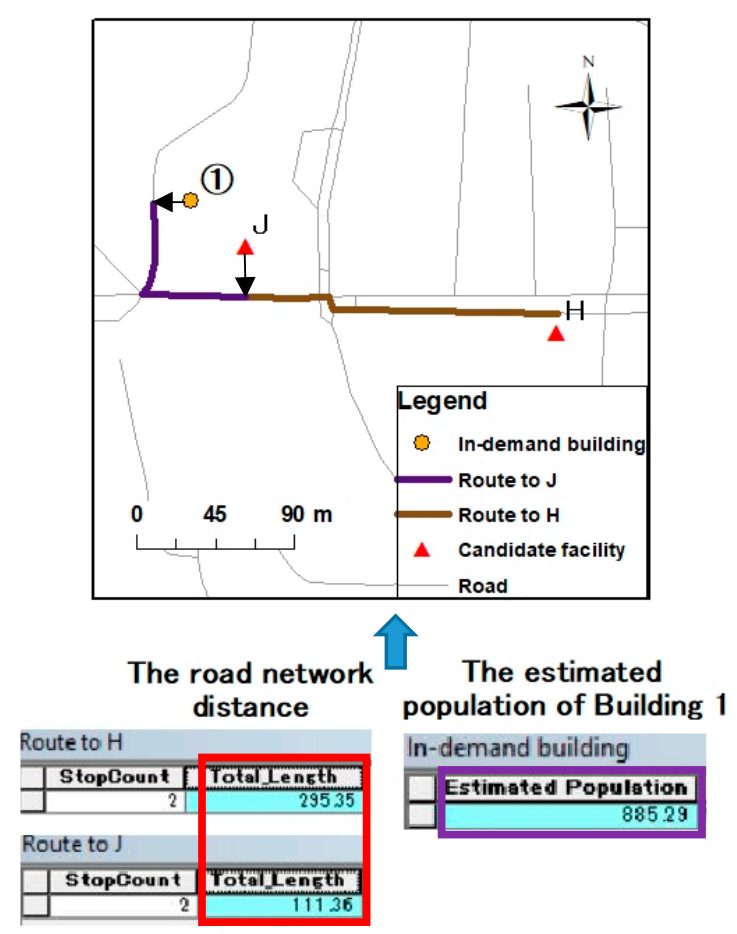

(b)

Figure 7. An example used in the calculation. (a) Allocation of PPP within $300 \mathrm{~m}$, and (b) road network route from Building 1 to PPP within $300 \mathrm{~m}$.

\section{Results}

\subsection{Criteria Weight and Facility Attractiveness}

Tables 4 and 5 show the result for the weights of the type of facility and the four criteria from the AHP judgments survey in the study area. Among the four types of facilities, the residents favored retail chain stores as PPPs (0.55), followed by private retail stores (0.29) and chain service stores (0.1). The results reveal that residents consider chain stores to be more reliable than individual stores and retail stores more attractive than service stores.

Table 4. Weight of facility type.

\begin{tabular}{ccc}
\hline Ranking & Type of facility & Weight \\
\hline 1 & Chain retail & 0.55 \\
2 & Private retail & 0.29 \\
3 & Chain service & 0.1 \\
4 & Private service & 0.06 \\
\hline
\end{tabular}


Table 5. Weight of criteria.

\begin{tabular}{ccc}
\hline Ranking & Criteria & Weight (Normalized) \\
\hline 1 & Business time & $56.3 \%$ \\
2 & Distance to bus & $28 \%$ \\
3 & stops/stations & $11.2 \%$ \\
4 & Facility type & $4.5 \%$ \\
\hline
\end{tabular}

The results for the weight criteria reveal that the attractiveness of a facility to residents was influenced mainly by its opening hours (56.3\%). Proximity to public transport (28\%) also played a significant role in attracting residents. The type of facility $(11.2 \%)$ was not very important relative to other factors, whereas the area of the facility $(4.5 \%)$ had the least impact on the attractiveness of the facility.

Table 6 and Figure 8 present the attractiveness value of 12 candidate facilities based on four criteria and their location in the study area. The most significant value of overall attractiveness was obtained for facility B (0.274), which is a retail chain store with the longest business hours and the shortest distance to the bus stop. This was followed by facility $\mathrm{H}(0.131)$ and facility I (0.096). The results show that the facility's business hours play a leading role in affecting the overall attractiveness of the facility. The top three facilities in terms of attractiveness were the top three facilities in terms of business hours, whereas the least attractive facility ranked last in business hours.

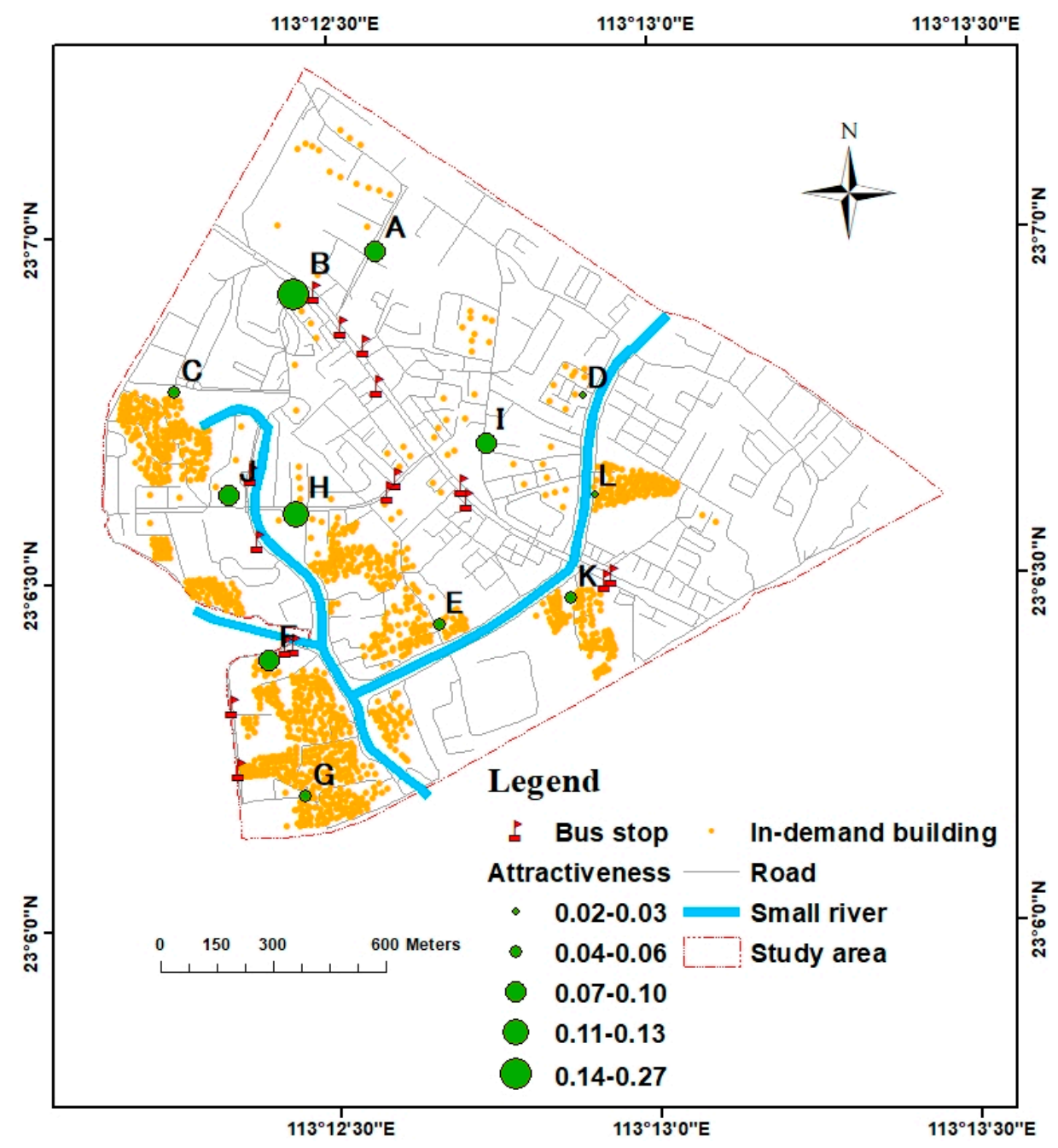

Figure 8. Attractiveness value of the facilities. 
Table 6. The attractiveness of the alternatives.

\begin{tabular}{cccccc}
\hline Criteria & Business Time & $\begin{array}{c}\text { Distance to Bus } \\
\text { Stops/Stations }\end{array}$ & Facility Area & Facility Type & $\begin{array}{c}\text { Overall } \\
\text { Attractiveness }\end{array}$ \\
\hline Weights & $\mathbf{5 6 . 3 0 \%}$ & $\mathbf{2 8 . 0 0 \%}$ & $\mathbf{4 . 5 0 \%}$ & $\mathbf{1 1 . 2 0 \%}$ & \\
\hline Facility A & 0.072 & 0.043 & 0.071 & 0.162 & $\mathbf{0 . 0 7 4}$ \\
Facility B & 0.346 & 0.211 & 0.048 & 0.162 & $\mathbf{0 . 2 7 4}$ \\
Facility C & 0.069 & 0.019 & 0.018 & 0.034 & $\mathbf{0 . 0 4 9}$ \\
Facility D & 0.036 & 0.011 & 0.093 & 0.034 & $\mathbf{0 . 0 3 1}$ \\
Facility E & 0.072 & 0.015 & 0.048 & 0.034 & $\mathbf{0 . 0 5 1}$ \\
Facility F & 0.049 & 0.176 & 0.15 & 0.034 & $\mathbf{0 . 0 8 8}$ \\
Facility G & 0.072 & 0.05 & 0.018 & 0.034 & $\mathbf{0 . 0 5 9}$ \\
Facility H & 0.149 & 0.096 & 0.048 & 0.162 & $\mathbf{0 . 1 3 1}$ \\
Facility I & 0.072 & 0.084 & 0.309 & 0.162 & $\mathbf{0 . 0 9 6}$ \\
Facility J & 0.029 & 0.147 & 0.15 & 0.162 & $\mathbf{0 . 0 8 2}$ \\
Facility K & 0.019 & 0.114 & 0.033 & 0.012 & $\mathbf{0 . 0 4 5}$ \\
Facility L & 0.015 & 0.034 & 0.014 & 0.012 & $\mathbf{0 . 0 2}$ \\
\hline
\end{tabular}

\subsection{Optimal Facilities Based on the Huff Model}

An index of facility attractiveness was estimated using the AHP method and incorporated into the Huff model. The service range and the predicted number of consumers for each candidate facility varied with the distance from the candidate facility to the residential building. Figure 9 illustrates the allocation of the in-demand buildings to the PPPs for distances of 300, 500, and $1000 \mathrm{~m}$. Figure 10 presents the ranking fluctuation of all candidate facilities in the distance range from $0 \mathrm{~m}$ to $1200 \mathrm{~m}$, according to the results of the Huff model.
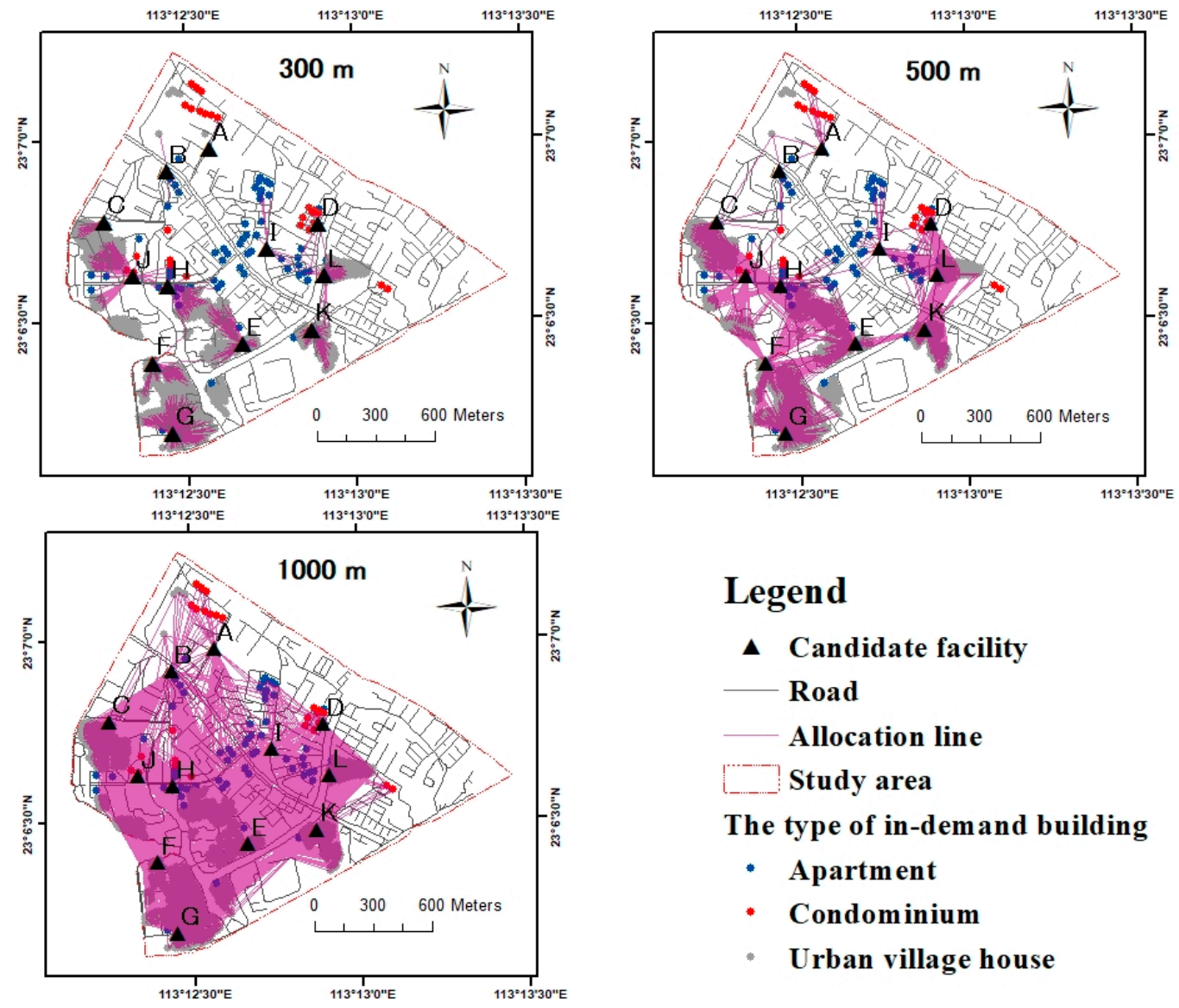

\section{Legend}

\ Candidate facility

Road

Allocation line

Study area

The type of in-demand building

- Apartment

- Condominium

- Urban village house

Figure 9. Allocation of PPPs to the in-demand buildings for three distances ( $300 \mathrm{~m}, 500 \mathrm{~m}$, and $1000 \mathrm{~m})$. 


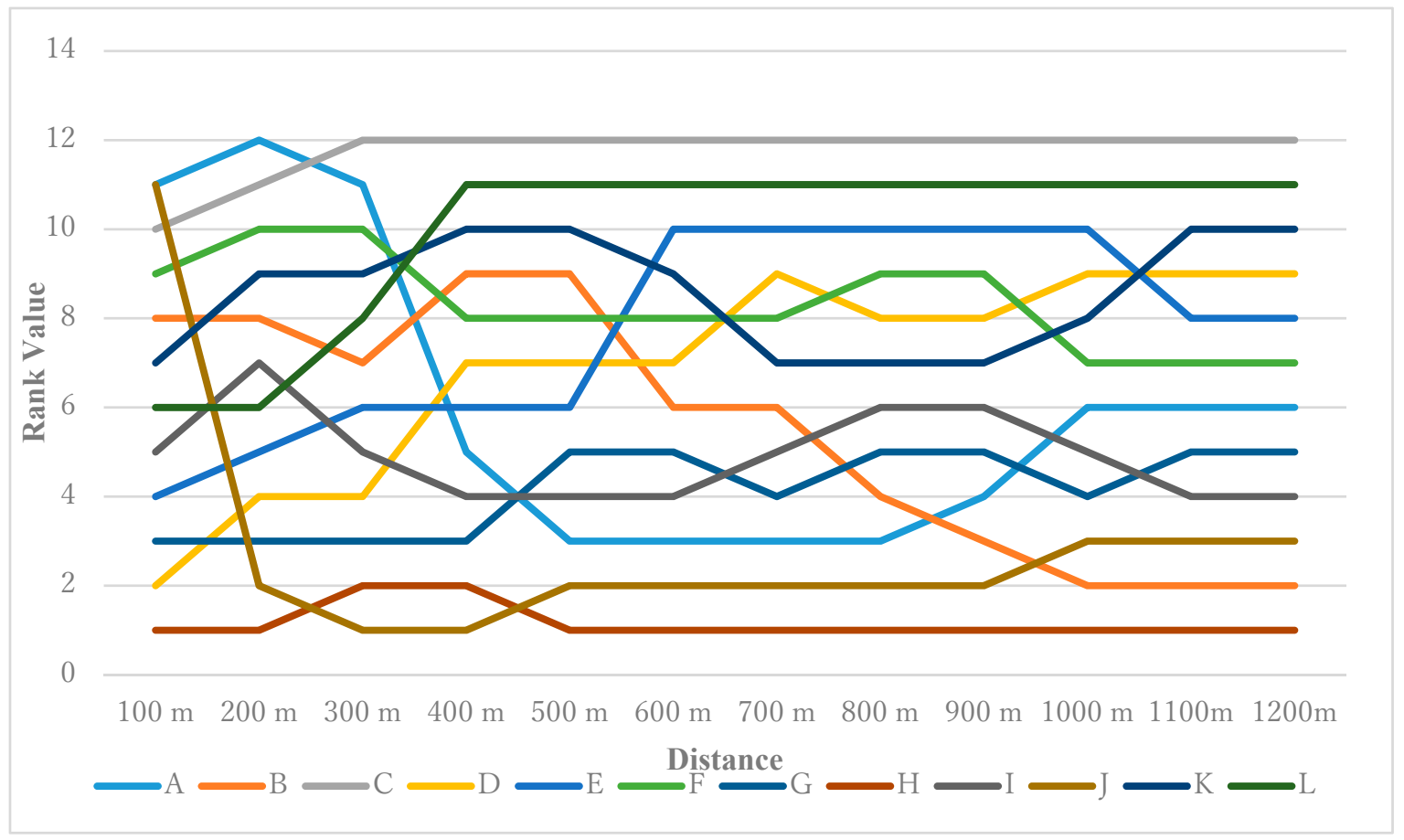

Figure 10. Ranking fluctuation of each candidate facility by different distances.

Within the distance of $300 \mathrm{~m}$, the high potential facilities were J, H, G, and D, which are located near the high-rise condominium area or densely built-up area of an urban village. Although the population of each building in an urban village is small, the large number of buildings means that the urban villages are densely populated.

For the distances between $300 \mathrm{~m}$ and $500 \mathrm{~m}$, the rankings of facilities $\mathrm{A}, \mathrm{D}, \mathrm{I}$, and L change significantly: facilities A and I move from low to high ranking, while facilities $\mathrm{D}$ and $\mathrm{L}$ move from high to low ranking. The ranking of facility A changed significantly because the high-rise condominium buildings in the vicinity of facility A were not within its $300 \mathrm{~m}$ service area. Facilities D, I, and L were located close to each other, and among these three facilities, facility I had the largest attractiveness value, whereas facility L had the lowest. As the service area was extended, some customers, who originally preferred facility D or L, chose facility I, due to its greatest attractiveness. Hence, the ranking fluctuation lines of facilities I, D, and L exhibited the opposite trend.

For the distances between $500 \mathrm{~m}$ and $1000 \mathrm{~m}$, the high ranking facilities were facilities $\mathrm{H}, \mathrm{J}, \mathrm{B}$, and A. In this interval, the most significant fluctuation in the ranking curve was facility B. It is observed that facility $B$ is located on the left side of the main road and close to the station, and its surrounding residential buildings have low density and only four apartments. When the distance extends to $1000 \mathrm{~m}$, the service area range of facility $B$ can cover the in-demand buildings that previously preferred other facilities. The ranking of facility $\mathrm{B}$ moved to second place because it has the highest attractiveness index.

For all of the distance ranges, the highest-ranked facility was almost always facility $\mathrm{H}$, followed by facilities $J$ and $G$. Facilities $H$ and $J$ are located in the middle of the area, surrounded by a large number of high-rise residential buildings or urban village buildings. Additionally, facility $\mathrm{H}$ has a higher attraction index than facility $\mathrm{J}$, so that customers are more likely to choose facility $\mathrm{H}$ than they are to choose facility J. Facility $\mathrm{G}$ is located in the lower part of the study area in a large urban village with a high density of residential buildings. We found that the facility with the highest potential was usually located in the high-density area that was more residential, and had a relatively higher attraction index. Facilities $C$ and $L$ were the lowest-ranked. One side of these facilities was close to the low-rise urban village residential building group, while the other side was close to the river and the flower wholesale market. The two facilities had a low attractiveness index, particularly facility L, 
which was ranked last. Facility $\mathrm{L}$ is a private service facility, with short business hours and a long distance to the bus stop. This kind of facility should not be used as a PPP.

\section{Discussion}

\subsection{Number of Potential Customers in the Facility's Service Range is the Main Factor for the Optimal Facility}

According to the results, all of the suitable facilities were concentrated in the high population density area, such as facilities J and $\mathrm{H}$ near the high-rise condominium community, and facility $\mathrm{G}$ near the large urban village. In these areas, the volume of the residential buildings is high due to either a large footprint or a high number of the floors in the buildings. Hence, the estimated allocated population is high. The results indicate that the number of customers is the primary factor influencing the suitability of the location of PPP. This is consistent with the results obtained in previous studies [16,18].

However, this study is limited by the data on the population demanding PPP services. We assumed the estimated building population in the blank service area is equal to the number of customers demanding the services since it is difficult to acquire the actual data for the population demanding the PPP service. Thus, improving the accuracy of predicting the population demanding the service can improve the accuracy of the calculation results of the model.

\subsection{Effects of Acceptable Distance to the Facility Ranking}

In this study, the developed hybrid model used the estimated buildings' population, the attractiveness of PPPs, and the distance between residential buildings and PPPs to predict the number of consumers for each candidate facility. Furthermore, we compared the rankings of all of the candidate facilities at different acceptable distances. Based on the ranking curve fluctuations, we found that the acceptable range determined the range of the in-demand building that affected the facility rank. Thus, determining the distance range should be considered important.

Residents may have different acceptable distances in different areas. In addition, the service range of PPPs may also vary between the different companies' planning strategies. Thus, the planners should first determine a suitable PPP service distance based on the various relevant scenarios, and then identify the corresponding optimal facility from the ranking fluctuation chart in light of the required distance range.

\subsection{Accuracy of the Geographical Barrier Constraint Affects the Accuracy of the Model Results}

The road network distance is more accurate and realistic compared to the Euclidean distance in the spatial analysis because it considers the geographical barrier constraints, such as rivers and the main road obstacles. In this study, the Euclidean distance between the candidate facility E and the opposite residential building group was less than $300 \mathrm{~m}$. However, they were separated by a river, and no bridge connected them directly. Consequently, in reality, the service area of candidate facility $\mathrm{E}$ cannot cover these residential buildings.

The road feature is an essential factor in network analysis. The use of detailed and updated road data improves the accuracy of the results. The classification of city roads in China usually includes four levels: expressway, main road, secondary road, and a branch road. In this research area, the road data consisted of the latter three. Considering that the resident's primary means of travel to pick up the parcel was walking, distinguishing the direction of the road was not necessary. Thus, we need to focus on the barrier on the residents' route in the road data. In the study area, only the main street had a road obstacle in the middle to divide it into two different directions. Using double lines to outline the main road and connecting these lines at zebra crossings and crossing bridges using ArcGIS software produces a result closer to reality. However, because secondary roads and branch roads have no geographical barriers, pedestrians can cross at any point. Using single lines to represent these roads is consistent with the fact that in China, convenience is associated with less walking. In 
the microscale case, the in-demand points are the location of the residential buildings. The streets connecting structures in the community areas also play a crucial role in the road network analysis. Consequently, the analysis results will be more realistic when more detailed and accurate road data are used in the study.

\subsection{Introduction of the AHP Method to Improve the Accuracy of Facility Attractiveness Value in the Huff Model}

The Huff model consists of three critical components: the in-demand location's population, facility attractiveness, and distance from an in-demand point to the facility. However, even the mere determination of the facility's attractiveness is difficult and ill-defined. The Huff model is widely used in business analysis [24], particularly in the retail industry. In the previous studies, the size of the facility was frequently used to calculate the attractiveness value. However, the size of the facility is an inaccurate determinant of facility attractiveness in the case of PPP because many other factors affect attractiveness. Moreover, the size of a facility is not one of the major influencing factors according to the results of the survey performed in the present study.

The AHP method is one of the best known and most widely used techniques in multi-factor decision-making approaches. In the AHP method, the affecting factors are determined first, and then the weight of the elements is calculated based on the results of the questionnaire for the pairwise comparison between the factors. Finally, the factors are quantified and combined with their respective weights to calculate the overall attractiveness of each candidate facility. The use of all of these rigorous steps yields an estimated attractiveness value of the facility that is close to reality.

The criteria of AHP are mostly determined through a survey of the literature. However, only a few studies have been performed for the factors affecting the attractiveness of PPPs. In this work, we attempt to survey PPP customers to determine the factors, so that we can directly collect the customer preferences from the actual users of PPP; this is a more accurate and realistic approach than the methods used in previous studies.

\subsection{The Facility's Attractiveness is More Sensitive to the Result of the Number of Customers in Case of a Long Acceptable Distance}

To understand the sensitivity of the facility's attractiveness to the number of customers, we compared all of the values obtained for the facilities under two kinds of facility attractiveness with varied distance range: an equal weight of 0.083 (the solid line) and the weight using AHP method (the dotted line) [53]. An examination of Figure 11 shows that the two lines representing most facilities coincide within $200 \mathrm{~m}$. As the distance increases, the difference between the two lines increases.

The Huff model analyzes the probability of customer selection of each facility in the contention area by considering the competition among all of the candidate facilities. Initially, there are nearly no overlapping contention areas between the facilities within a short distance so that the Huff model cannot affect the results. In this case, the number of customers depends only on the number of inhabitants in the service area of each facility. As the acceptable distance increases, the overlapping contention area of the service areas between the candidate facilities grows. In Figure 11, the results of the 12 facilities are displayed in the order of the value of attractiveness, and the difference between the two lines was found to have no apparent relationship with the magnitude of attractiveness.

Therefore, the Huff model has no effect on the results until the overlapping contention areas appear. The influence of the Huff model on the results, and the sensitivity of the results to the attractiveness value of the facility both increase with increasing contention service area. For a considerable service distance, the decision-maker should invest more effort in improving the accuracy of the estimate of the facility attractiveness because the error in this estimate may affect the accuracy of the final results, and consequently, result in the wrong location being selected. 


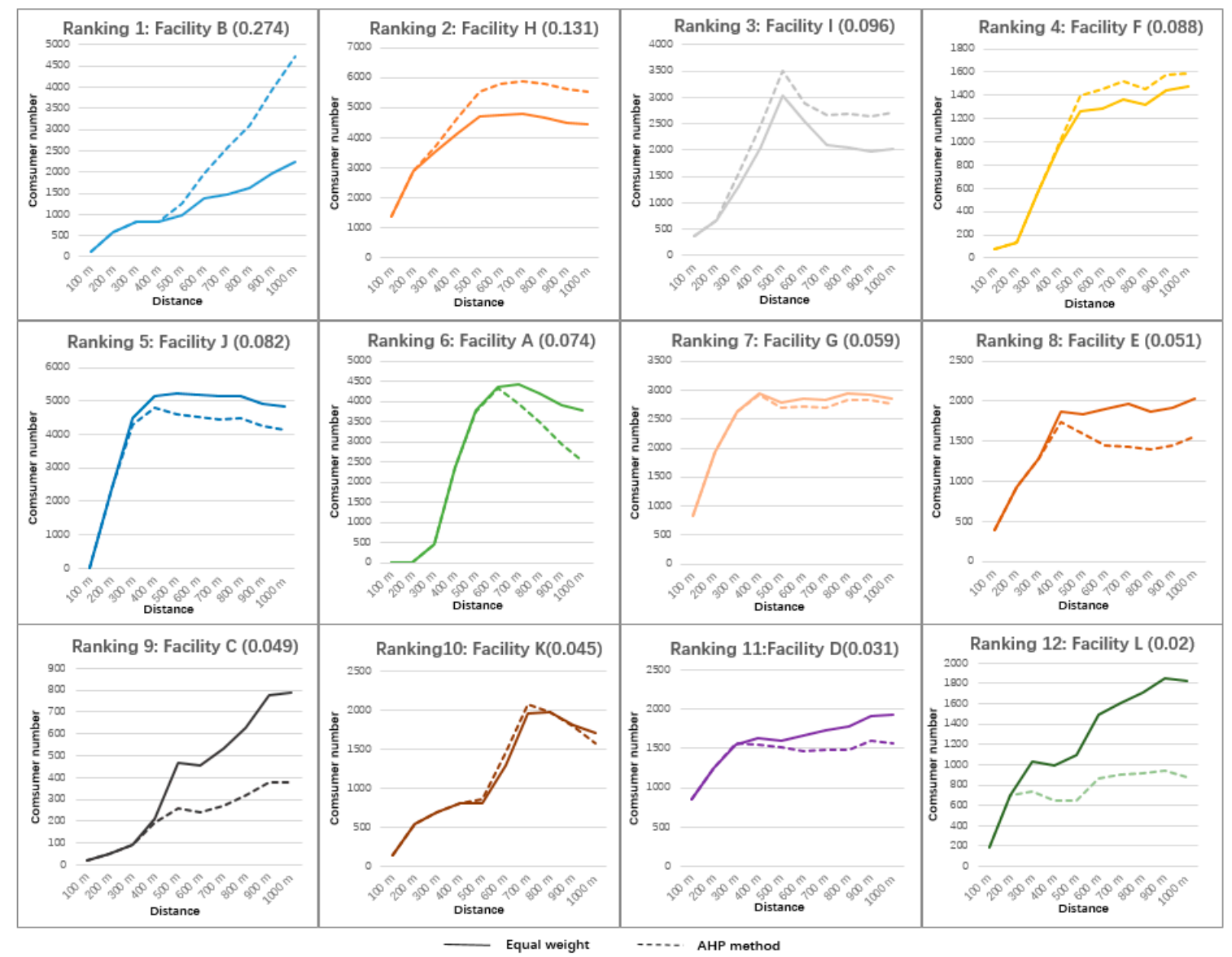

Figure 11. Sensitivity of consumer numbers by two types of facility attractiveness with a varied range.

\section{Conclusions}

With the fast-paced development of e-commerce in China, the problem of the last mile in logistics (low efficiency and high cost) is getting worse and becoming a bottleneck for e-commerce development. The logistics of express delivery companies are not sufficient enough to meet the business volume and the demands of consumers. To settle this problem, China's largest internet e-commerce company, Ali Baba, introduced parcel pick-up stations in local facilities with cooperation. However, research on how this system was planned is scarce.

This paper proposed a combination of the Huff model and the AHP method in the GIS software environment to analyze the optimal location of PPP. In the three critical components of the Huff model, facility attractiveness is vaguely defined and difficult to quantify. We introduced the AHP method to improve the accuracy of yielded facility attractiveness values. Instead of determining attractiveness factors by summarizing the scarce literature on PPPs or depending on expert opinion, we administered a survey to establish the four criteria of PPP attractiveness: facility's business opening hours, convenience to public transportation, facility type, and facility area. The dominant factor affecting facility attractiveness is the operation time (56.3\%), followed by the convenience of public transportation (28\%). Facility attractiveness was estimated using the AHP method and incorporated into the Huff model. The Huff model considers the competition between the facility's appeal and the distance from the facility to residential buildings, extrapolating the number of theoretical customers in each candidate facilities. Finally, we generated the ranking fluctuations diagram of all the candidate facilities at various ranges that the decision-makers can find optimal facilities by the PPP service distance they need.

This planning procedure is feasible and more realistic for planners. It can be applied in the different study areas and cases to select the optimal location from various options or identify a priority 
list of candidate facilities from the fluctuation ranking graph. The study revealed the significance of certain factors in influencing the attractiveness of the PPP; the number of customers in the service area of a facility was the main factor influencing the suitability of a facility as a PPP. The optimal facility should have high attractiveness with long business hours, a large area, be convenient in terms of access to public transportation, and be a chain retail store. The study finally shows that the service area analyzed by the road network distance is closer to reality than the Euclidean distance. The accuracy of the geographical barrier constraint affects the accuracy of the results, and the attractiveness of the facility has a strong effect on the number of customers in the case of a long acceptable distance. This study provided a way of helping the decision-maker settle the complicated PPP selection problem from the visualization of the ranking of candidates in different distance conditions.

Compared to the previous approaches towards finding the optimal location using discrete siting or maximum coverage, this study provides another perspective of considering the contention of the candidate facilities and the various service distances to determine the importance ranking list of candidates. A decision-maker can select the highest-ranking facility based on the service distance they need or on the overall ranking of all service distance to the optimal facility for PPP. It may be helpful for decision-makers to occupy the best resources in the fastest time. Although this approach has not pointed out the number of optimization settings, it can help decision-makers create a priority list of candidate facilities based on rankings. In the highly competitive terminal market, occupying the most crucial candidate facility can give companies a competitive advantage in terms of time capital.

Author Contributions: Conceptualization, Zilai Zheng, Takehiro Morimoto, and Yuji Murayama; Methodology, Zilai Zheng, Takehiro Morimoto, and Yuji Murayama; Software, Zilai Zheng; Validation, Zilai Zheng; Formal Analysis, Zilai Zheng; Investigation, Zilai Zheng; Resources, Zilai Zheng; Data Curation, Zilai Zheng; Writing-Original Draft Preparation, Zilai Zheng; Writing-Review and Editing, Takehiro Morimoto and Yuji Murayama; Visualization, Zilai Zheng; Supervision, Takehiro Morimoto and Yuji Murayama All authors have read and agreed to the published version of the manuscript.

Funding: This research received no external funding.

Acknowledgments: The comments and suggestions of the reviewers and editors are gratefully acknowledged.

Conflicts of Interest: The authors declare no conflict of interest.

\section{References}

1. Balcik, B.; Beamon, B.M.; Smilowitz, K. Last mile distribution in humanitarian relief. J. Intel. Transp. Syst. 2008, 12, 51-63. [CrossRef]

2. Cárdenas, I.; Beckers, J.; Vanelslander, T. E-commerce last-mile in Belgium: Developing an external cost delivery index. Res. Transp. Bus. Manag. 2017, 24, 123-129. [CrossRef]

3. Dablanc, L.; Liu, Z.; Combes, F.; Koning, M.; Coulombel, N.; Blanquart, C.; Heitz, A.; Klauenberg, J.; de Oliveira, L.K.; Seidel, S. CITYLAB Deliverable 2.1, Observatory of Strategic Developments Impacting Urban Logistics (2018 Version), Report for the European Commission 2018. Available online: http: //www.citylab-project.eu/deliverables/D2_1.pdf (accessed on 23 February 2020).

4. Edwards, J.B.; McKinnon, A.C.; Cullinane, S.L. Comparative analysis of the carbon footprints of conventional and online retailing: A "last mile" perspective. Int. J. Phys. Distrib. Logist. Manag. 2010, 40, 103-123. [CrossRef]

5. Gevaers, R.; Van de Voorde, E.; Vanelslander, T. Characteristics and typology of last-mile logistics from an innovation perspective in an urban context. In City Distribution and Urban Freight Transport: Multiple Perspectives; Macharis, C., Melo, S., Eds.; Edward Elgar Publishing: Cheltenham, UK, 2011; pp. 56-71. [CrossRef]

6. Gevaers, R.; Van de Voorde, E.; Vanelslander, T. Cost modelling and simulation of last-mile characteristics in an innovative B2C supply chain environment with implications on urban areas and cities. Procedia Soc. Behav. Sci. 2014, 125, 398-411. [CrossRef]

7. Wong, C.Y.; Karia, N. Explaining the competitive advantage of logistics service providers: A resource-based view approach. Int. J. Prod. Econ. 2010, 128, 51-67. [CrossRef] 
8. Mokhtarian, P.L. A conceptual analysis of the transportation impacts of B2C e-commerce. Transportation 2004, 31, 257-284. [CrossRef]

9. McKinnon, A.C.; Tallam, D. Unattended delivery to the home: An assessment of the security implications. Int. J. Retail Distrib. Manag. 2003, 31,30-41. [CrossRef]

10. Punakivi, M.; Yrjölä, H.; Holmström, J. Solving the last mile issue: Reception box or delivery box. Int. J. Phys. Distrib. Logist. Manag. 2001, 31, 427-439. [CrossRef]

11. Junjie, X.; Min, W. Convenient pickup point in e-commerce logistics: A theoretical framework for motivations and strategies. Comput. Model. New Technol. 2013, 17, 209-213.

12. Xiao, Z.; Wang, J.J.; Lenzer, J.; Sun, Y. Understanding the diversity of final delivery solutions for online retailing: A case of Shenzhen, China. Transp. Res. Procedia 2017, 25, 985-998. [CrossRef]

13. Slabinac, M. Innovative solutions for a "Last-Mile" delivery-A European experience. In Proceedings of the 15th International Scientific Conference Business Logistics in Modern Management, Osijek, Croatia, 15 October 2015; pp. 111-130.

14. Wang, J.J.; Xiao, Z. Co-evolution between etailing and parcel express industry and its geographical imprints: The case of China. J. Transp. Geogr. 2015, 46, 20-34. [CrossRef]

15. Yuen, K.F.; Wang, X.; Ng, L.T.W.; Wong, Y.D. An investigation of customers' intention to use self-collection services for last-mile delivery. Transp. Policy 2018, 66, 1-8. [CrossRef]

16. Morganti, E.; Dablanc, L.; Fortin, F. Final deliveries for online shopping: The deployment of pickup point networks in urban and suburban areas. Res. Transp. Bus. Manag. 2014, 11, 23-31. [CrossRef]

17. Collins, A.T. Behavioural Influences on the Environmental Impact of Collection/ delivery Points. In Green Logistics and Transportation; Springer: New York, NY, USA, 2015; pp. 15-34. [CrossRef]

18. Roy, S.K.; Shekhar, V.; Lassar, W.M.; Chen, T. Customer engagement behaviors: The role of service convenience, fairness and quality. J. Retail. Consum. Serv. 2018, 44, 293-304. [CrossRef]

19. Tan, R.; Xu, Y.; Chen, D.; Liu, L. Research on the spatial distribution of pickup points from the perspective of residents' behavior. World Reg. Stud. 2016, 25, 111-120.

20. Zhang, H.Y.; Shang, X. Analysis of express industry in the last mile distribution pattern-Taking as an example and rookie Inn Feng nest. Transp. Manag. World 2015, 22, 48-51.

21. Church, R.L. Geographical information systems and location science. Comput. Oper. Res. 2002, 29, 541-562. [CrossRef]

22. Hernandez, T. Enhancing retail location decision support: The development and application of geovisualization. J. Retail. Consum. Serv. 2007, 14, 249-258. [CrossRef]

23. Joerin, F.; Thériault, M.; Musy, A. Using GIS and outranking multicriteria analysis for land-use suitability assessment. Int. J. Geogr. Inf. Sci. 2001, 15, 153-174. [CrossRef]

24. Huff, D.L. Defining and estimating a trading area. J. Mark. 1964, 28, 34-38. [CrossRef]

25. Huff, D.L. Parameter estimation in the Huff model. ESRI ArcUser 2003, October-December, 34-36.

26. Suárez-Vega, R.; Santos-Peñate, D.R.; Dorta-González, P.; Rodríguez-Díaz, M. A multi-criteria GIS based procedure to solve a network competitive location problem. Appl. Geogr. 2011, 31, 282-291. [CrossRef]

27. Coutinho-Rodrigues, J.; Simão, A.; Antunes, C.H. A GIS-based multicriteria spatial decision support system for planning urban infrastructures. Decis. Support Syst. 2011, 51, 720-726. [CrossRef]

28. Kousalya, P.; Reddy, G.M.; Supraja, S.; Prasad, V.S. Analytical Hierarchy Process approach-An application of engineering education. Math. Aeterna 2012, 2, 861-878.

29. Mckinsey Global Institute. China and the World. Available online: https://www.mckinsey.com/ \{\}/media/ mckinsey/featured\%20insights/china/china\%20and\%20the \%20world \%20inside\%20the\%20dynamics\% 20of\%20a\%20changing\%20relationship/mgi-china-and-the-world-full-report-june-2019-vf.ashx (accessed on 23 February 2020).

30. State Post Bureau of the People's Republic of China. Statistical Communique on the Development of Postal Industry in 2018. Available online: http://www.spb.gov.cn/xw/dtxx_15079/201905/t20190510_1828821.html (accessed on 23 February 2020).

31. State Post Bureau of the People's Republic of China. Statistical Communique on the Development of Postal Industry in 2017. Available online: http://www.spb.gov.cn/xw/dtxx_15079/201806/t20180604_1581131.html (accessed on 23 February 2020). 
32. State Post Bureau of the People's Republic of China. Statistical Communique on the Development of Postal industry in 2016. Available online: http://www.spb.gov.cn/xw/dtxx_15079/201705/t20170503_1150869.html (accessed on 23 February 2020).

33. State Post Bureau of the People's Republic of China. Statistical Communique on the Development of Postal Industry in 2015. Available online: http://www.spb.gov.cn/xw/dtxx_15079/201605/t20160510_757698.html (accessed on 23 February 2020).

34. State Post Bureau of the People's Republic of China. Statistical Communique on the Development of Postal Industry in 2014. Available online: http://www.spb.gov.cn/xw/dtxx_15079/201504/t20150429_462010.html (accessed on 23 February 2020).

35. Guangzhou Statistics Bureau. Available online: http:/tjj.gz.gov.cn/tjsj/index.html (accessed on 23 February 2020).

36. Gaode Maps. Available online: https://ditu.amap.com/ (accessed on 23 February 2020).

37. Lianjia Real Estate Agency. Available online: https://gz.lianjia.com/ (accessed on 23 February 2020).

38. Wu, F.; Li, L.H.; Han, S.Y. Social sustainability and redevelopment of urban villages in China: A case study of Guangzhou. Sustainability 2018, 10, 2116. [CrossRef]

39. Baidu Coordinate System. Available online: http://api.map.baidu.com/lbsapi/getpoint/index.html (accessed on 23 February 2020).

40. Lwin, K.; Murayama, Y. A GIS approach to estimation of building population for micro-spatial analysis. Transact. GIS 2009, 13, 401-414. [CrossRef]

41. Wind, Y.; Saaty, T.L. Marketing applications of the analytic hierarchy process. Manag. Sci. 1980, 26, 641-658. [CrossRef]

42. Chuansheng, X.; Dapeng, D.; Shengping, H.; Xin, X.; Yingjie, C. Safety evaluation of smart grid based on AHP-entropy method. Syst. Eng. Procedia 2012, 4, 203-209. [CrossRef]

43. Russo, R.; Camanho, R. Criteria in AHP: A systematic review of literature. Procedia Comput. Sci. 2015, 55, 1123-1132. [CrossRef]

44. Masoud, R.G.; Farimah, M.R.; Maryam, G. Portfolio selection: A fuzzy-ANP approach. Financ. Innov. 2020, 6. [CrossRef]

45. Saaty, T.L. Theory and Applications of the Analytic Network Process: Decision Making with Benefits, Opportunities, Costs, and Risks; RWS Publications: Pittsburgh, PA, USA, 2005.

46. Goepel, K.D.; Performance, B. Comparison of judgment scales of the analytical hierarchy process-A New Approach. Int. J. Inf. Technol. Decis. Mak. 2019, 18, 445-463. [CrossRef]

47. Simwanda, M.; Murayama, Y.; Ranagalage, M. Modeling the drivers of urban land use changes in Lusaka, Zambia using multi-criteria evaluation: An analytic network process approach. Land Use Policy 2020, 92, 104441. [CrossRef]

48. Goepel, K.D. Implementation of an online software tool for the analytic hierarchy process (AHP-OS). Int. J. Anal. Hierarchy Process 2018, 10. [CrossRef]

49. Harker, P.T. Incomplete pairwise comparisons in the analytic hierarchy process. Math. Model. 1987, 9, 837-848. [CrossRef]

50. Oliva, G.; Setola, R.; Scala, A. Sparse and distributed analytic hierarchy process. Automatica 2017, 85, $211-220$. [CrossRef]

51. Pan, H.; Li, Y.; Dang, A. Application of network Huff model for commercial network planning at suburban-Taking Wujin district, Changzhou as a case. Ann. GIS 2013, 19, 131-141. [CrossRef]

52. Dramowicz, E. Retail Trade Area Analysis Using the Huff Model. Dir. Mag. 2005. Available online: https://www.directionsmag.com/article/3207 (accessed on 23 February 2020).

53. Derdouri, A.; Murayama, Y. Onshore wind farm suitability analysis using gis-based analytic hierarchy process: A case study of fukushima prefecture, Japan. Geoinfor Geostat: An Overv. 2018, S3. [CrossRef]

(C) 2020 by the authors. Licensee MDPI, Basel, Switzerland. This article is an open access article distributed under the terms and conditions of the Creative Commons Attribution (CC BY) license (http://creativecommons.org/licenses/by/4.0/). 